CHRONIC OBSTRUCTIVE PULMONARY DISEASE

\title{
Deaths from chronic obstructive pulmonary disease in France, 1979-2002: a multiple cause analysis
}

\author{
C Fuhrman, E Jougla, J Nicolau, D Eilstein, M-C Delmas

See end of article for authors' affiliations

\section{Correspondence to:} Dr C Fuhrman, Institut de Veille Sanitaire, 12 rue du Val d'Osne, 94415 SaintMaurice Cedex, France; c.fuhrman@invs.sante.fr

Received 1 March 2006 Accepted 9 May 2006 Published Online First 31 May 2006

\begin{abstract}
Background: A study was undertaken of deaths with an underlying or associated cause of chronic obstructive pulmonary disease (COPD), and trends in COPD mortality from 1979 to 2002 in France were analysed.

Methods: Data were obtained from the Centre of Epidemiology on the Medical Causes of Death (CépiDc) for individuals aged 45 years and over. Owing to implementation of ICD-10 in 2000 for recording causes of death, two separate periods were analysed (1979-99 and 2000-2).

Results: In 2000-2, COPD was the underlying cause of $1.4 \%$ of deaths (deaths from COPD) and was mentioned on the death certificate in $3.0 \%$ (deaths with COPD). The other main underlying causes in these cases were cardiovascular diseases (32.0\%) and cancers (24.5\%). In 1979-99, age standardised rates of death with COPD remained stable in men $(-0.01 \% /$ year $)$ and increased in women $(+1.7 \% /$ year $)$. The mean annual rates of death with COPD per 100000 were 84 for men and 19 for women in 2000-2. Conclusion: Multiple cause analysis improved the estimate of COPD related mortality. In 1979-99, COPD related mortality rates in France were stable in men but increased in women. Implementation of ICD-10 in 2000 introduced substantial discontinuities in mortality trends.
\end{abstract}

C hronic obstructive pulmonary disease (COPD) is a leading cause of morbidity and mortality. It was ranked as the sixth leading cause of death worldwide in 1990 and the fourth in the USA in 2002. ${ }^{1}$ Morbidity and mortality from COPD increased in most countries, including the USA, the UK, and Canada through the beginning of the 1990s. ${ }^{2-4}$ Over the past decade the mortality rates have remained stable among men but continued to rise among women. Analysis of COPD mortality trends in France from 1969 to the end of 1983 showed increases for both sexes, with a more gradual increase in women than in those in North America. ${ }^{5}$ Tobacco use is the main risk factor for COPD. Other risk factors include occupational exposure, genetic factors, air pollution, and passive tobacco exposure. COPD is a slow progressive disease, and the damage triggered by tobacco persists for many years after cessation. Thus, decreases in smoking rates will affect mortality trends only several decades later. ${ }^{6}$ Using only the underlying cause of death for chronic diseases such as COPD dramatically underestimates the overall disease burden. A multiple cause analysis that estimates disease related mortality by taking into account all the conditions listed on the death certificate is particularly warranted in these cases. ${ }^{7-10}$

This study of French mortality rates from 1979 to the end of 2002 aimed to:

- describe the characteristics of deaths for which COPD was mentioned on the death certificate as either the underlying cause or anywhere on the death certificate (multiple cause analysis);

- characterise the association at death between COPD and other specific diseases; and

- analyse trends in COPD related mortality.

\section{METHODS}

Mortality data were obtained from the Centre of Epidemiology for Medical Causes of Death (CépiDcINSERM). Medical death certificates contain two sections in which physicians enter the medical conditions of the deceased. Part I asks for the underlying cause of death (that is, the disease that initiated the chain of events resulting in death) and the sequence leading directly to death (intermediate and direct causes). Part II allows the physician to list other conditions that contributed to the death but were not part of the direct causal sequence. Coding rules of the International Classification of Diseases (ICD) ultimately select the underlying cause of death. Associated causes of death are all other significant conditions that contributed to it. Until 1999, CépiDc used ICD-9 to code causes of death for entry in the national death statistics database, and recorded for each death a maximum of two associated causes (in addition to the immediate and underlying causes of death). Since 2000, when ICD-10 was implemented and manual coding was replaced by an automated coding system, all causes reported by physicians have been recorded.

The analyses here concern deaths from 1979 to the end of 2002 of adults who were living and died in France (excluding French overseas territories). Because deaths involving COPD are unlikely before the age of 45 years, the analysis focused on the population aged 45 years and older.

Descriptive analyses were conducted for cases with COPD recorded as the underlying cause (death from COPD) or mentioned anywhere on the certificate (death with COPD). The codes for COPD in ICD-9 are: 490 (unspecified bronchitis), 491 (chronic bronchitis), 492 (emphysema), and 496 (chronic obstruction not elsewhere classified). The ICD-10 codes are: J40 (unspecified bronchitis), J41-42 (chronic bronchitis), J43 (emphysema), and J44 (other obstructive pulmonary disease). The relation between the ICD-9 and ICD-10 codes is not quite that simple, however, because ICD-9 treated chronic respiratory failure (CRF) as an imprecise cause of death (coded 496) while, in ICD-10, this diagnosis has been moved to the respiratory chapter (J961). To compare ICD-9 and ICD-10 data more accurately, we also

Abbreviations: COPD, chronic obstructive pulmonary disease; $C R F$ chronic respiratory failure; EAPC, estimated annual percentage change 
Table 1 Characteristics of deaths with COPD or with COPD or CRF in adults aged 45 years or over in France, 2000-2

\begin{tabular}{lll}
\hline & $\begin{array}{l}\text { Underlying } \\
\text { cause }\end{array}$ & Any mention \\
\hline COPD & & \\
Mean annual number of deaths & 7167 & 14995 \\
Mean (SD) age & $80.1(10.4)$ & $79.2(10.5)$ \\
Male/female ratio & 2.1 & 2.3 \\
COPD or CRF & & \\
Mean annual number of deaths & 9516 & 23437 \\
Mean (SD) age & $79.9(10.2)$ & $78.8(10.3)$ \\
Male/female ratio & 1.9 & 2.0 \\
\hline
\end{tabular}

COPD, chronic obstructive pulmonary disease; CRF, chronic respiratory failure; $S D$, standard deviation.

analysed the 2000-2 data by combining COPD (as defined above) and CRF deaths. The contribution of multiple cause analysis was assessed by calculating a "multiple to underlying ratio", defined as the number of deaths with COPD (or COPD+CRF) divided by the number of deaths from COPD (or COPD+CRF). ${ }^{10}$

Owing to the substantial changes in mortality recording that occurred in 2000, the analysis of time trends in COPD mortality was restricted to the 1979-9 data. Population figures provided by the French National Institute for Statistics and Economic Studies (INSEE) were used to calculate the crude and 5 year age specific mortality rates for each calendar year. Age standardised rates (direct method) were calculated by applying the age specific rates to the 1976 European population of adults aged 45 years or older. Estimated annual percentage changes (EAPC) were used to summarise trends by fitting linear regression models to the logarithms of the death rates with time as the independent variable, on the assumption that the change in mortality rates over time was constant.

\section{RESULTS}

In 2000-2, COPD was mentioned as the underlying cause of death for a mean number of 7167 deaths per year of persons aged 45 years or older in France, and anywhere on the death certificate for 14995 deaths $(1.4 \%$ and $3.0 \%$, respectively, of all deaths; table 1). The male/female ratio was 2.1 and the mean age was 80.1 years. The multiple to underlying ratio was 2.1. It was higher for men than women $(2.2 v 1.9)$ and decreased with increasing age (from 2.3 for those aged 5054 years to 1.7 for those aged 95 years or more). When COPD and CRF were combined, the mean number of annual deaths rose to 9516 for underlying causes ( $1.9 \%$ of all deaths) and 23437 for all listed causes (4.7\% of all deaths).

For the same period, we also compared the underlying causes of deaths with COPD as an associated cause and those of deaths without any mention of COPD (table 2). Ischaemic heart disease and lung cancer, both also smoking related diseases, were more likely ( 1.5 and 2.1 times, respectively) to be the underlying cause of death when COPD was mentioned than when it was not. Asthma was listed as the underlying cause on a mean of $124(1.6 \%)$ death certificates annually that mentioned COPD as an associated cause, and as a contributing cause on $183(2.7 \%)$ death certificates listing COPD as the underlying cause. Over the same period, a mean of 1216 deaths were attributed to asthma each year with no mention of COPD. Tobacco use disorder (ICD-10 F17) was listed on $13.5 \%$ of the death certificates with COPD (15.8\% for men and $8.1 \%$ for women).

The multiple to underlying ratio for deaths with CRF but without any mention of COPD was 3.6. Cardiovascular diseases $(27.3 \%)$ and cancer $(14.6 \%)$ were the main underlying causes of death when CRF but not COPD was mentioned. Asthma was the underlying disease more often with CRF $(2.2 \%)$ as an associated cause than with COPD (1.6\%), or with neither CRF nor COPD (0.3\%). The frequencies of lung cancer and ischaemic heart disease as the underlying disease when CRF was an associated cause were similar to those observed in deaths with neither COPD nor CRF $(5.1 \% \vee 4.9 \%$ for lung cancer, and $8.6 \% \vee 8.8 \%$ for ischaemic heart disease, $\mathrm{p}>0.05$ for both).

The mean annual number of deaths from COPD fell dramatically from 1998-9 through 2000-2 (table 3). The largest decreases involved deaths from unspecified or chronic bronchitis $(-84 \%$ and $-63 \%$, respectively). Deaths from chronic obstruction not elsewhere classified (ICD-9 496) fell by $41 \%$ if compared with the equivalent code under ICD-10 (other obstructive pulmonary disease, J44) but only 13\% if compared with other obstructive pulmonary disease or CRF $(\mathrm{J} 44+\mathrm{J} 961)$. Similar results were found for deaths with COPD (data not shown).

From 1979 to the end of 1999 the crude annual mortality rates from COPD increased among men $(+12 \%)$ and women $(+76 \%)$. Similar trends were observed for deaths with COPD ( $+21 \%$ among men and $+78 \%$ among women). For the $2000-$ 2 period the mean crude annual mortality rate from COPD was 45.0/100 000 among men and 18.1/100 000 among women, while that with COPD was $97.7 / 100000$ for men and 34.9/100 000 for women.

From 1979 to the end of 1999 the annual age standardised rates of death from COPD decreased slightly among men (EAPC $-0.7, \mathrm{p}<0.001$ ) but increased steadily among women

Table 2 Mean annual number of deaths according to underlying cause among deaths with COPD as an associated cause and among deaths without any mention of COPD in adults aged 45 years or more, France, 2000-2002

\begin{tabular}{llll}
\hline Underlying diseaset & $\begin{array}{l}\text { COPD as associated } \\
\text { cause } \\
\text { (N=7828) }\end{array}$ & $\begin{array}{l}\text { Deaths without COPD } \\
\text { (N=484560) }\end{array}$ & $\begin{array}{l}\text { Adjusted RR* } \\
\text { (95\% Cl) }\end{array}$ \\
\hline $\begin{array}{l}\text { Cardiovascular diseases } \\
\quad \text { Ischaemic heart disease }\end{array}$ & $2506(32.0 \%)$ & $104768(21.6 \%)$ & $1.49(1.46$ to 1.52$)$ \\
Cancer & $1064(13.6 \%)$ & $42470(8.8 \%)$ & $1.54(1.49$ to 1.59$)$ \\
$\quad$ Lung cancer & $1914(24.5 \%)$ & $137342(28.3 \%)$ & $0.86(0.84$ to 0.88$)$ \\
Cerebrovascular diseases & $776(9.9 \%)$ & $23558(4.9 \%)$ & $2.09(2.01$ to 2.17$)$ \\
Lower respiratory infections & $182(5.5 \%)$ & $36508(7.5 \%)$ & $0.72(0.69$ to 0.76$)$ \\
Asthma & $180(2.3 \%)$ & $14865(3.1 \%)$ & $0.78(0.20$ to 0.85$)$ \\
Other & $124(1.6 \%)$ & $1216(0.3 \%)$ & $6.40(5.75$ to 7.11$)$ \\
\hline
\end{tabular}

*Relative risk of having a given disease as the underlying cause of death, adjusted for age. †Cardiovascular diseases: ICD-10 100-I15 \& I20-I52; ischaemic heart disease: ICD-10 I20-I25; cancer: ICD-10 C00-C32 \& C33-C97; lung cancer: ICD-10 C33-C34; cerebrovascular diseases: ICD-10 160-169; low respiratory infections (bronchopneumonia, influenza, acute bronchitis): ICD-10 J10-J18 \& J20-J22; asthma: ICD-10 J45-46. 
Table 3 Mean annual number of deaths from COPD or CRF by ICD codes in adults aged 45 years or more in France, 1998-9 and 2000-2

\begin{tabular}{|c|c|c|c|}
\hline \multicolumn{2}{|l|}{$1998-1999(\mathrm{~N}=15350)$} & \multicolumn{2}{|l|}{$2000-2002(N=9516)$} \\
\hline ICD-9 & n (\%) & ICD-10 & n (\%) \\
\hline $\begin{array}{l}\text { 490: unspecified bronchitis } \\
\text { 491: chronic bronchitis } \\
\text { 492: emphysema } \\
\text { 496: chronic obstruction not } \\
\text { elsewhere classified }\end{array}$ & $\begin{array}{l}3743(24.4) \\
2516(16.4) \\
737(4.8) \\
8354(54.4)\end{array}$ & $\begin{array}{l}\text { J40: unspecified bronchitis } \\
\text { J41-J42: chronic bronchitis } \\
\text { J43: emphysema } \\
\text { J44: other obstructive pulmonary } \\
\text { disease } \\
\text { J961: chronic respiratory failure }\end{array}$ & $\begin{array}{l}592(6.2) \\
942(9.9) \\
690(7.3) \\
4943(51.9) \\
2349(24.8)\end{array}$ \\
\hline
\end{tabular}

(EAPC $+1.4, \mathrm{p}<0.001$; table 4 , fig 1$)$. They fell significantly among men in all age groups, except those aged 85 years or more. The rates for women fell significantly in the youngest group (45-54 years) and rose significantly among those aged 65 years or more.

When all deaths with COPD were taken into account there was a trend towards an increase-that is, either reduced decreases or pronounced increases (fig 2). The overall EAPC for deaths with COPD was $-0.01(\mathrm{p}>0.05)$ among men and $+1.7(\mathrm{p}<0.001)$ among women. Regardless of the definition used (COPD $v$ COPD or CRF; underlying cause $v$ any mention), the age standardised rates for the period 2000-2 were lower than those observed in previous years (figs 1 and 2 ). The mean annual rates per 100000 of death from COPD were 38.9 in men and 9.7 in women, while those of death with COPD were 84.3 in men and 19.1 in women.

\section{DISCUSSION}

COPD was mentioned on death certificates in 3\% of all deaths in France of adults aged 45 years or older during the period $2000-2$. It was the underlying cause of $48 \%$ of deaths for which COPD was mentioned anywhere on the certificate. Since 2000, all causes of death listed on death certificates have been recorded, and the multiple to underlying ratio ( 1.7 in 1999) increased to 2.1 in 2000-2. The latter ratio is close to that reported in the USA (2.3) but higher than that reported in England (1.7), ${ }^{911}$ perhaps due to differences in recording of co-morbidities. The multiple to underlying ratio was higher for men than for women, as elsewhere, ${ }^{11}{ }^{12}$ and it decreased with increasing age because fewer co-morbid conditions were recorded for the elderly.

Incontrovertibly, considering only the underlying cause of death underestimates the global burden of chronic disease. ${ }^{9}$ Even after taking into account all deaths with COPD, the assessment of its contribution to mortality-while much more comprehensive-remains underestimated. COPD is widely undiagnosed even during its severe stages. ${ }^{13-15}$ A study conducted in the USA found that nearly half the individuals with forced expiratory volume in 1 second $<50 \%$ had not been diagnosed with COPD. ${ }^{16}$ Moreover, even diagnosed COPD is underreported on death certificates (both as the underlying and contributing causes)..$^{17}$

Multiple cause analysis makes it possible to describe the associations between COPD and other specific diseases at death. Cardiovascular diseases and cancer were, with COPD itself, the main underlying causes of death on death certificates mentioning COPD. The risk of dying from cardiovascular disease or lung cancer was significantly higher when COPD was mentioned as a contributing diagnosis than when it was not. This is to be expected: not only do these diseases share a risk factor (tobacco exposure), but COPD is a risk factor for lung cancer and cardiovascular mortality. ${ }^{19}$ Tobacco use, listed on $13.5 \%$ of death certificates with COPD in 2000-2, was obviously underreported. Nonetheless, recording of smoking has increased dramatically in France in recent years (from $1.1 \%$ in 1979 to $6.2 \%$ in 1999) and reflects, as described earlier for the USA, ${ }^{9}$ better awareness of the dangers of tobacco.

From 1979 to the end of 1999, the age standardised rates of death with COPD levelled off among men $(-0.01 \%$ per year $)$ in France but increased among women $(+1.7 \%$ per year $)$. The sex difference in time trends is consistent with smoking behaviour and with other international data. Goldacre et $\mathrm{al}^{7}$ analysed COPD mortality in an English population from 1979 to 1998 and found that the trends in age standardised rates were similar for women $(+1.7 \%$ per year for death with COPD with the increase greatest for those older than 65 years) while the rates for men fell by $-2.5 \%$ per year. The mortality

Table 4 Mean annual age standardised rates* of mortality from COPD by age group and sex in adults aged 45 years or more in France, 1979-99

\begin{tabular}{|c|c|c|c|c|c|c|}
\hline Age group (years) & $1979-81$ & $1984-86$ & $1989-91$ & 1994-96 & 1998-99 & EAPC \\
\hline \multicolumn{7}{|l|}{ Men } \\
\hline $45-54$ & 8.1 & 6.0 & 4.8 & 4.4 & 4.9 & $-3.2 \dagger$ \\
\hline $55-64$ & 27.2 & 29.7 & 24.1 & 22.4 & 20.6 & $-1.7 \dagger$ \\
\hline $65-74$ & 98.7 & 100.8 & 86.3 & 86.6 & 88.6 & $-0.9 \dagger$ \\
\hline $75-84$ & 329.8 & 340.4 & 300.5 & 287.1 & 290.7 & $-0.9 \dagger$ \\
\hline $85+$ & 830.3 & 937.8 & 868.3 & 847.9 & 914.6 & $+0.2 \ddagger$ \\
\hline Overall & 81.6 & 85.6 & 75.6 & 74.0 & 75.4 & $-0.7 \dagger$ \\
\hline \multicolumn{7}{|l|}{ Women } \\
\hline $45-54$ & 1.6 & 1.8 & 1.4 & 1.1 & 1.4 & $-1.9 \S$ \\
\hline $55-64$ & 5.3 & 5.5 & 5.4 & 4.9 & 5.2 & $-0.5 \ddagger$ \\
\hline $65-74$ & 19.3 & 21.2 & 19.9 & 21.1 & 23.6 & $+0.8 \S$ \\
\hline $75-84$ & 75.4 & 81.3 & 83.6 & 86.4 & 93.4 & $+1.1 \dagger$ \\
\hline $85+$ & 277.1 & 309.6 & 348.5 & 366.0 & 407.3 & $+2.3 \dagger$ \\
\hline Overall & 20.1 & 22.0 & 22.8 & 24.6 & 25.9 & $+1.4 \dagger$ \\
\hline
\end{tabular}

EAPC, estimated annual percentage change.

*Rates (per 100000 ) standardised to the 1976 European population.

$\dagger p<0.001 ; \neq p<0.05 ; \S p<0.01$ 


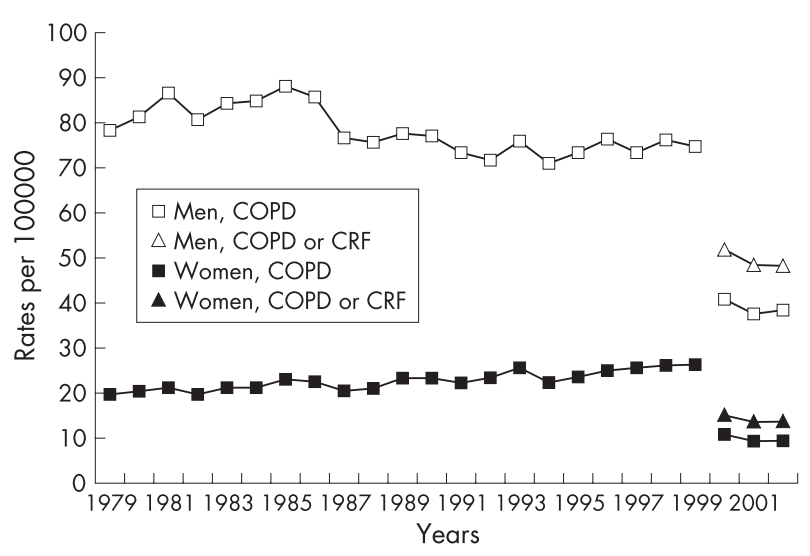

Figure 1 Annual age standardised (to the 1976 European population) rates of death from COPD in adults aged 45 years or more in France, 1979-99 (ICD-9) and 2002-2 (ICD-10). COPD, chronic obstructive pulmonary disease; CRF, chronic respiratory failure.

rates in the USA increased in women from 1979 to 2000 but remained stable in men from 1984 onwards. ${ }^{39}$ Canadian studies report similar trends, including stabilisation among men and doubling among women. ${ }^{4}$ As shown previously in England and Wales, ${ }^{20}$ the differences in time trends according to age that we observed suggest a birth cohort effect, which probably reflects lifelong differences in smoking behaviour and environmental exposure.

Several important changes in the recording of causes of death took place in 2000 in France. ICD-10, with twice as many codes as in ICD-9 and important changes in coding rules, represents the greatest change in the ICD in over 50 years. Bridge coding between ICD- 9 and ICD-10 showed that the latter's impact differed in France and elsewhere, according to the cause of death (marked for respiratory and infectious diseases but low for neoplasms or circulatory system diseases). ${ }^{21} 22$ An automated coding system that makes it possible to record all causes mentioned on the death certificate was implemented at the same time as ICD10. The automated coding system is based on the algorithm included in the US Mortality Medical Data System and results from an extensive international collaboration intended to improve the reliability, homogeneity, and comparability of the process of coding mortality data. These modifications inevitably produce apparent discontinuities in mortality trends, and it is difficult to disentangle the separate impact of each modification. We note, however, that the dramatic shift seen in France is in part due to the improvement in the process of coding mortality data to meet international standards. There were fewer deaths from COPD in 2000-2 than in 1998-9, even taking into account deaths from CRF. This impact was also observed on mortality with COPD; because of the increased number of associated causes recorded in the database $(72 \%$ of death certificates with COPD listed had more than two associated causes in 2002-2), the rate of mortality with COPD or CRF in 2000-2 should have been higher than that with COPD in 1998-9. We found fewer deaths with unspecified or chronic bronchitis in 2000-2 than in 1998-9. Some of them are now being coded as acute bronchitis (J20) or as other obstructive pulmonary disease (J44). Changes in listings for CRF are also complex. ICD-9 code 496 probably included deaths with CRF not due to COPD. However, under ICD-10 and with all causes of death recorded, it is less likely that an individual who dies from COPD will be coded as CRF without COPD. Because deaths with CRF but without COPD have rather different characteristics than deaths from COPD, inclusion of CRF

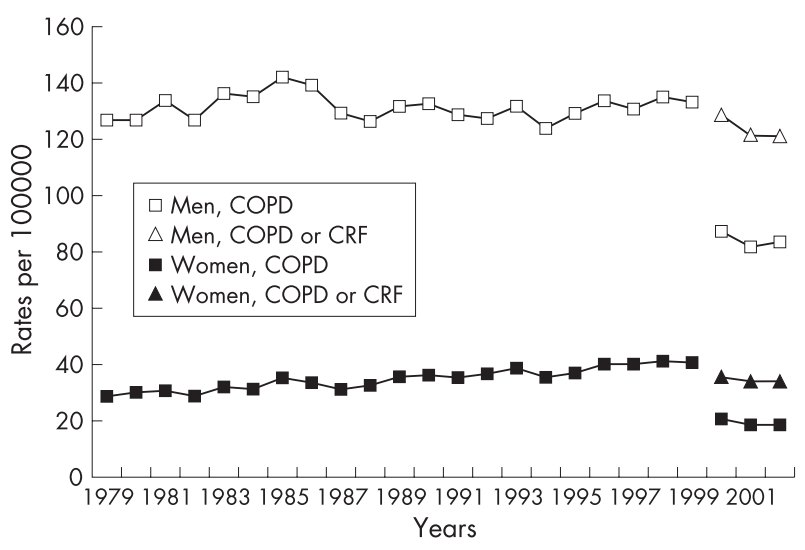

Figure 2 Annual age standardised (to the 1976 Europen population) rates of death with COPD in adults aged 45 years or more in France, 1979-99 (ICD-9, $\leqslant 2$ associated causes recorded) and 2000-2 (ICD10, all associated causes recorded). COPD, chronic obstructive pulmonary disease; CRF, chronic respiratory failure.

deaths in the analysis of future COPD mortality trends appears unjustified.

Mortality rates from COPD remain lower in France than in North America or northern Europe. In 1999 the age specific mortality rates per 100000 from COPD for adults aged 6574 years were 175 in the USA, ${ }^{3} 204$ for men and 132 for women in the $\mathrm{UK}^{23}$ and 87 for men and 23 for women in France. Some authors analyse obstructive lung disease as a whole, including asthma. ${ }^{39}$ These conditions are often difficult to distinguish among the elderly, and misdiagnosis appears to be related to sex and smoking habits. Some deaths attributed to asthma may be undiagnosed COPD, especially among women and non-smokers. On the other hand, some deaths with COPD recorded may also be undiagnosed asthma or asthma with fixed airflow limitation. ${ }^{24}$ We did not include asthma in the COPD deaths we studied. When they were included, however, the mortality trends were unchanged (data not shown), and the age standardised rates remained lower in France (41.5/100 000 for men and 13.2/100 000 for women as the underlying cause in 2002) than in the USA or UK.

These large between-country differences have been described previously. ${ }^{2525}$ They obviously reflect differences in tobacco exposure. In France, tobacco sales pattern since 1860 (first data available) show an increase until 1975 (mainly from 1945) and a decrease from 1991.2027 The smoking epidemic was weaker and occurred later than in the USA or UK: the mean daily number of cigarettes sold per adult inhabitant peaked at 11 in the USA in the 1960s, nine in the UK in the early 1970s, and six in France in 1975. Other risk factors, including environmental or occupational exposures and socioeconomic factors, have also been advanced to explain the higher mortality rates found in the UK until the 1990s. ${ }^{2}$

While a recent study estimates the prevalence of chronic bronchitis at $4.1 \%$ among adults aged 25 years or more, ${ }^{13}$ data on the prevalence of COPD in France remain sparse. The European Community Respiratory Health Survey (ECRHS), conducted among young adults aged 20-44 years, found large differences from one country to another in the prevalence of COPD which may be related to smoking patterns but also to environmental or genetic factors. ${ }^{28} 29$ The prevalence of COPD in France was among the lowest ( $1.5 \%$ compared with $3.3 \%$ in the UK and $4.8 \%$ in the USA).

The other explanation may be greater underdiagnosis of COPD in France. In the USA and UK, COPD and emphysema (ICD-9 496 and 492) accounted for 90\% of the death 
certificate mentions of obstructive lung disease compared with $60 \%$ in France. Terms used in clinical practice undoubtedly differ between countries, but the widespread use of the term bronchitis rather than COPD by French physicians probably also reflects underdiagnosis of COPD.

In conclusion, multiple cause of death analysis improved the estimation of the contribution of COPD to mortality. From 1979 to the end of 1999, COPD related mortality rates were stable in men and increased in women in France, consistent with smoking patterns. Given the long latency period between the start of smoking and the onset of COPD (and the still longer time to death), it can be assumed that deaths with COPD will continue to increase, particularly among women. Implementation of ICD-10 in 2000, together with the use of an automated coding system, has led to important discontinuities in mortality trends but should improve comparability of mortality data between countries.

\section{Authors' affiliations}

C Fuhrman, J Nicolau, D Eilstein, M-C Delmas, Institut de Veille

Sanitaire, Saint-Maurice, France

E Jougla, Centre of Epidemiology on the Medical Causes of Death (CépiDc), INSERM, Le Vésinet, France

Funding: none.

Competing interests: none declared.

\section{REFERENCES}

1 Jemal A, Ward E, Hao Y, et al. Trends in the leading causes of death in the United States, 1970-2002. JAMA 2005;294:1255-9.

2 Pride NB, Soriano JB. Chronic obstructive pulmonary disease in the United Kingdom: trends in mortality, morbidity, and smoking. Curr Opin Pulm Med 2002;8:95-101.

3 Mannino DM, Homa DM, Akinbami $\sqcup$, et al. Chronic obstructive pulmonary disease surveillance-United States, 1971-2000. MMWR CDC Surveillance Summaries 2002;51:1-16

4 Lacasse Y, Brooks D, Goldstein RS. Trends in the epidemiology of COPD in Canada, 1980 to 1995. COPD and Rehabilitation Committee of the Canadian Thoracic Society. Chest 1999;116:306-13.

5 Cooreman J, Henry C, Neukirch C. Mortality by respiratory disease in ten European and North American countries (1979-1990). Rev Mal Respir 1996;13:47-53.

6 Feenstra TL, van Genugten ML, Hoogenveen RT, et al. The impact of aging and smoking on the future burden of chronic obstructive pulmonary disease: a model analysis in the Netherlands. Am J Respir Crit Care Med 2001; 164:590-6.

7 Goldacre MJ, Duncan M, Cook-Mozaffari P, et al. Mortality rates for common respiratory diseases in an English population 1979-1998: artefact and substantive trends. J Public Health 2004;26:8-12.

8 Jougla E, Papoz L, Balkau B, et al. Analysis of diabetes-related mortality in France (1970-1987) from multiple causes of death. Diabet Metab $1991 ; 17: 337-45$
9 Mannino DM, Brown C, Giovino GA. Obstructive lung disease deaths in the United States from 1979 through 1993. An analysis using multiple-cause mortality data. Am J Respir Crit Care Med 1997;156:814-8.

10 Israel RA, Rosenberg HM, Curtin LR. Analytical potential for multiple cause-ofdeath data. Am J Epidemiol 1986;124:161-79.

11 Hansell AL, Walk JA, Soriano JB. What do chronic obstructive pulmonary disease patients die from? A multiple cause coding analysis. Eur Respir J 2003:22:809-14.

12 Wall MM, Huang J, Oswald J, et al. Factors associated with reporting multiple causes of death. BMC Med Res Methodol 2005;5:4.

13 Huchon GJ, Vergnenegre A, Neukirch F, et al. Chronic bronchitis among French adults: high prevalence and underdiagnosis. Eur Respir J 2002;20:806-12.

14 Sobradillo Pena V, Miravitlles M, Gabriel R, et al. Geographic variations in prevalence and underdiagnosis of COPD: results of the IBERPOC multicentre epidemiological study. Chest 2000;118:981-9.

15 Coultas DB, Mapel D, Gagnon R, et al. The health impact of undiagnosed airflow obstruction in a national sample of United States adults. Am J Respir Crit Care Med 2001;164:372-7

16 Petty TL. Scope of the COPD problem in North America: early studies of prevalence and NHANES III data: basis for early identification and intervention. Chest 2000;117:326-31S.

17 Camilli AE, Robbins DR, Lebowitz MD. Death certificate reporting of confirmed airways obstructive disease. Am J Epidemiol $1991 ; 133: 795-800$.

18 Mannino DM, Buist AS, Petty TL, et al. Lung function and mortality in the United States: data from the First National Health and Nutrition Examination Survey follow up study. Thorax 2003;58:388-93.

19 Sin DD, Wu L, Man SF. The relationship between reduced lung function and cardiovascular mortality: a population-based study and a systematic review of the literature. Chest 2005;127:1952-9.

20 Lee PN, Fry JS, Forey BA. Trends in lung cancer, chronic obstructive lung disease, and emphysema death rates for England and Wales 1941-85 and their relation to trends in cigarette smoking. Thorax 1990;45:657-65.

21 Anderson RN, Minino AM, Hoyert DL, et al. Comparability of cause of death between ICD-9 and ICD-10: preliminary estimates. Natl Vital Stat Rep 2001;49:1-32.

22 Pavillon G, Boileau J, Renaud G, et al. Conséquences des changements de codage des causes médicales de décès sur les données nationales de mortalité en France, à partir de l'année 2000. Bull Epidemiol Hebdomadaire 2005;4:13-6.

23 National Statistics. Review of the Registrar General on deaths by cause, sex and age, in England and Wales, 1999, Series DH2, No.26. London: Stationery Office, 2000, 1-253. http://www.statistics.gov.uk/downloads/ theme_health/DH2_26_1999/DH2_26.pdf.

24 Meyer PA, Mannino DM, Redd SC, et al. Characteristics of adults dying with COPD. Chest 2002;122:2003-8.

25 Thom TJ. International comparisons in COPD mortality. Am Rev Respir Dis 1989; 140:S27-34.

26 Cooreman J, Thom TJ, Higgins MW. Mortality from chronic obstructive pulmonary diseases and asthma in France, 1969-1983. Comparisons with the United States and Canada. Chest 1990;97:213-9.

27 Hill C, Laplanche A. Tabagisme et mortalité: aspects épidémiologiques. Bull Epidemiol Hebdomadaire 2003;22-23:98-100.

28 Cerveri I, Accordini S, Verlato G, et al. Variations in the prevalence across countries of chronic bronchitis and smoking habits in young adults. Eur Respir $J$ 2001;18:85-92.

29 de Marco R, Accordini S, Cerveri I, et al. An international survey of chronic obstructive pulmonary disease in young adults according to GOLD stages. Thorax 2004;59:120-5. 